the whole suggests that ascorbic acid is ineffective against the gingivitis commonly found in this country' according to Magee (1946). We badly need precise information about the nutriture in Britain at the present time.

\title{
REFERENCES
}

Adcock, E. W., Hammond, W. H. \& Magee, H. E. (1947). 7. Hyg., Camb., 45, 65.

Adcock, E. W. \& Magee, H. E. (1945). Mon. Bull. Minist. Hlth, 4, 136.

Adcock, E. W. \& Magee, H. E. (r946a). Mon. Bull. Minist. Hlth, 5, 36.

Adcock, E. W. \& Magee, H. E. (1946b). Mon. Bull. Minist. Hlth, 5, 198.

Adcock, E. W., Magee, H. E. \& Milligan, E. H. M. (1947). Mon. Bull. Mirtist. Hlth, 6, 54.

Clarke, S. H. (1936). Nature, Lond., 137, 535.

Committee on Haemoglobin Surveys (1945). Spec. Rep. Ser. med. Res. Coun., Lond., no. 252.

Jones, R. H. (1938). F.R. statist. Soc. ror, r.

Magee, H. E. (1944). Mon. Bull. Minist. Hlth, 3, 146.

Magee, H. E. (1946). Brit. med. F. i, 475.

Spearman, C. (1904). Amer. F. Psychol. 15, 268.

Wolbach, S. B. (1945). Nutr. Rev. 3, 193.

\section{An Example of Difficulties in the Assessment of Nutritional Status}

\author{
By C. C. Ungley, Royal Victoria Infirmary, Newcastle-upon-Tyne
}

Some difficulties in the assessment of nutritional status are best illustrated by quoting a case.

After unaccustomed exercise a casual labourer developed oedema. Non-nutritional causes were excluded. The diet was poor because of duodenal ulcer pain, vomiting and poverty. Caries impeded mastication. Pre-war white bread, margarine, jam, sugar, tea, fish, potatoes and beer supplied $c$. $1700 \mathrm{Cal}$. and $0.5 \mathrm{mg}$. of vitamin $\mathrm{B}_{1}$ daily. The ratio of vitamin $B_{1}$ to non-fat calories slightly exceeded the accepted minimum requirement for his weight.

In Britain beriberi* seldom arises from dietary deficiency alone. In this patient, foods held up for $24 \mathrm{hr}$. by duodenal stenosis grew abundant yeasts, known to absorb vitamin $B_{1}$ and render it unavailable.

Apart from oedema, signs included intermittent tachycardia, wide pulse pressure with arterial sounds audible at zero, warm extremities, normal circulation time, slightly raised venous pressure, abnormal electrocardiograms, depressed deep reflexes, tender calves and plantar dysaesthesia. Adrenalin reduced diastolic pressure to zero. Vitamin $B_{1}$ excretion was negligible; response to loading doses, poor. Apparent vitamin $B_{1}$ in blood (Sinclair, 1939 ) was low.

During control and test periods the diet, low in vitamin $\mathrm{B}_{1}$, was weighed but unrestricted in amount. Oedema twice disappeared with rest in bed, only to reappear when the patient was allowed up. Weight changes mirrored these fluctuations. Eventually oedema increased, dyspnoea and substernal pain recurred.

- The term beriberi, used here for brevity, is by some authors applied to the syndrome only when it affects rice-eating peoples in tropical countries. Since multiple deficiencies are the rule, this condition is not necessarily synonymous with $B_{1}$ avitaminosis. 
Two single doses of $\mathrm{I} \mathrm{mg}$. of vitamin $\mathrm{B}_{1}$ on successive days produced dramatic effects. Diuresis began within $36 \mathrm{hr}$., oedema disappeared, weight fell, the appetite increased, and the food consumption rose steeply. Diastolic blood pressure increased and arterial sounds were no longer audible at zero. The adrenalin test became negative. After 5 days electrocardiograms were within normal limits. Improvement persisted for 6 weeks, during which no further vitamin $B_{1}$ was given. Calf tenderness disappeared. Deep reflexes returned much later when $5 \mathrm{mg}$. of vitamin $B_{1}$ was administered daily and diet was unrestricted.

This case illustrates six steps in diagnosis: ( 1 ) non-nutritional causes wereexcluded; (2) nutritional causes were demonstrated; diagnosis was supported by (3) other signs, (4) functional tests and (5) vitamin estimations; (6) a therapeutic test was positive.

No single approach was adequate. Many patients without beriberi eat poor diets and excrete little vitamin $\mathrm{B}_{1}$. Functional tests and other signs were not pathognomonic. Even the therapeutic test would have been misleading without control of diet and exercise.

The application of a 'battery of methods' can be further exemplified by studies in polyneuritis (Ungley, 1939).

\title{
REFERENCES
}

Sinclair, H. M. (1939). Biochem. Y. 33, 2027.

Ungley, C. C. (1939). Proc. 3rd Int. Neurol. Congr., Copenhagen, p. 829.

\section{Remarks on Anthropometric and Performance Tests}

\author{
By E. R. BRANSBy, Ministry of Health, Whitehall, London, S.W. I
}

I had hoped that Yudkin ( 1948 ) would have dealt briefly with recent work on child development and then discussed where we stand. There are many matters in his paper on which I would have liked to comment, but propose to restrict my discussion to five somewhat unrelated points, which I have not time to develop in detail.

\section{Group data}

The average heights and weights of groups of children of various ages are sensitive indices of past or present environment, provided, of course, that genetic factors do not interfere. Such data are an essential part of public health statistics, and their collection and analysis should be designed to meet the needs of each individual locality. For example, data for the different social classes collected over a number of years in Liverpool show whether the differences between the social classes are contracting or expanding. There is little point at present in presenting more than straightforward height and weight averages by age and sex, except perhaps repetitive measurements on the same children, although there is no doubt that further research will show how growth data can be used in an even more sensitive way. 